This manuscript was accepted and published by Biomass and Bioenergy.

Publication data of the final, corrected work:

Várhegyi, G.; Szabó, P.; Antal, M. J., Jr.: Kinetics of the thermal decomposition of cellulose under the experimental conditions of thermal analysis. Theoretical extrapolations to high heating rates. Biomass Bioenergy 1994, 7, 69-74. doi: $\underline{10.1016 / 0961-9534(95) 92631-\mathrm{H}}$

\title{
KINETICS OF THE THERMAL DECOMPOSITION OF CELLULOSE UNDER THE EXPERIMENTAL CONDITIONS OF THERMAL ANALYSIS. THEORETICAL EXTRAPOLATIONS TO HIGH HEATING RATES.
}

\author{
Gábor Várhegyi and Piroska Szabó \\ Hungarian Academy of Sciences, Research Laboratory for Inorganic Chemistry, \\ Email: varhegyi.gabor@t-online.hu or gvarhegyi@gmail.com \\ and \\ Michael Jerry Antal, Jr.
}

Hawaii Natural Energy Institute and the Department of Mechanical Engineering, University of Hawaii at Manoa, Honolulu, Hawaii 96822

\begin{abstract}
Thermobalance - mass spectrometer (TG-MS) experiments carried out by the authors in a period of 8 years are reviewed and analyzed. Celluloses and lignocellulosic biomass samples were studied. The data are evaluated by the method of least squares. The results indicate that a single rate controlling reaction step dominates the kinetics of the cellulose decomposition at low heating rates $\left(2-20^{\circ} \mathrm{C} / \mathrm{min}\right)$ provided that the heat and mass transport problems are experimentally eliminated and the amount of catalytic impurities is reduced by dilute acid or hot water washing treatments. The kinetic parameters obtained from the experiments with different cellulose and biomass samples evidenced only ca. 8 percent scattering. A simple explanation is given for the kinetic compensation effect observed. Theoretical extrapolations are presented to predict the behavior of extremely small, idealized cellulose samples at high heating rates.
\end{abstract}

Keywords: Cellulose, Biomass, Thermal Decomposition, Thermogravimetry, Pyrolysis, Reaction Kinetics, Kinetic Compensation Effect 


\section{INTRODUCTION}

Cellulose is generally believed to decompose by the Broido - Shafizadeh mechanism ${ }^{1-3}$ :

Cellulose $\longrightarrow$ "Active cellulose" $\longrightarrow$ dehydrocellulose $\rightarrow \ldots$

where $\mathrm{k}_{\mathrm{A}}$ and $\mathrm{k}_{\mathrm{B}}$ are the rate constant of a dehydration and a depolymerization type reaction, respectively.

The dehydration reaction $\left(\mathrm{k}_{\mathrm{A}}\right)$ appears at low temperatures, below $300^{\circ} \mathrm{C}$, and can be detected by inserting of long, $21 \mathrm{~h}$ isothermal sections into the heating program. ${ }^{2}$ At higher temperatures, the thermal degradation to monomer-type products $\left(\mathrm{k}_{\mathrm{B}}\right)$ becomes dominant. If no long isothermal sections are applied during the heating of the cellulose, approximately first order decomposition appears. Agrawal ${ }^{4}$ gives a detailed list of earlier papers dealing with the description of cellulose pyrolysis by first order reaction kinetics and emphasizes the importance of the heat transfer problems in the experiments. The present authors observed simple first order reaction kinetic behavior ${ }^{5}$ in experiments where the moderate heating rates and the low sample masses excluded the possibility of serious heat transfer problems.

Whole biomass samples consisting of cellulose, hemicellulose and lignin can approximately be described by the sum of first order reactions ${ }^{5,6}$ :

$-\mathrm{d} m / \mathrm{d} t=\sum c_{j} \mathrm{~d} \alpha_{j} / \mathrm{d} t$

$\mathrm{d} \alpha_{j} / \mathrm{d} t=A_{j} \exp \left(-E_{j} / \mathrm{R} T\right)\left(1-\alpha_{j}\right)$

where $m$ is the sample mass divided by its initial value and $\alpha_{j}$ is the fraction of volatiles which escaped from component $j$ until time $t$. As it will be discussed later, a physical meaning can be attributed to equation (3) when it describes the decomposition of the cellulose moiety of the samples. For the thermal decomposition of lignin and hemicellulose equation (3) is only a formal mathematical approximation. Coefficients $c_{j}$ express the contribution of the partial processes to the overall mass loss. Hence $c_{j}$ is proportional to the concentration of the $j$ th component in the sample:

$c_{j}=(\text { concentration })_{j} *(\text { yield } \text { of volatiles })_{j}$

Since inorganic impurities have strong catalytic effects on cellulose decomposition, equations (2)- (4) are applicable only if the amount of impurities is reduced by a dilute acid or a hot-water washing procedure. ${ }^{6}$ This type of modelling may help, among others, in the resolution of the multipeak $-\mathrm{d} m / \mathrm{d} t$ curves of the 
biomass materials and, in this way, to get information about the behavior of cellulose in whole biomass samples.

Reaction scheme (1) and equations (2) - (4) are valid only if the reaction products are allowed to escape from the decomposing sample. The presence of the reaction products during the decomposition starts autocatalytic reactions and turns the process exothermic. ${ }^{7,8}$

In the present paper we shall briefly review and analyse the results of our experiments carried out in the last 8 years and, using the considerations outlined above, we shall make extrapolations from the experimental conditions of thermal analysis to predict the behavior of extremely small, idealized cellulose samples at high heating rates.

\section{EXPERIMENTAL}

\subsection{Equipment and numerical calculations}

The experiments were carried out using a Perkin - Elmer TGS-2 thermobalance with a $140 \mathrm{ml} / \mathrm{min}$ flow of Ar. To minimize heat and mass transfer problems, small samples (2-3 mg) were distributed in a sample pan of $6 \mathrm{~mm}$ diameter. The heating rates varied between 2 and $80^{\circ} \mathrm{C} / \mathrm{min}$. The data acquisition was computerized and the DTG was determined by differentiation of smoothing splines. The reliability of the DTG curves were carefully checked in special test experiments. ${ }^{9}$ Since their error was found negligible and the differentiation of a TG curve quasi magnifies the features characteristic of the partial peaks, the DTG curves were evaluated by the method of the least squares. Denoting the points of a DTG curve and the corresponding $-\mathrm{d} m / \mathrm{d} t$ values calculated from the kinetic model by $-(\mathrm{d} m / \mathrm{d} t)_{i}{ }^{\text {exper }}$ and $-(\mathrm{d} m / \mathrm{d} t)_{i}{ }^{c a l c}$, respectively, the sum of squares to be minimized has the following form:

$S=\sum\left[(\mathrm{d} m / \mathrm{d} t)_{i}{ }^{\text {exper }}-(\mathrm{d} m / \mathrm{d} t)_{i}{ }^{\text {calc }}\right]^{2}$

The calculations were carried out on an AT-386 compatible computer. The thermobalance employed is part of a thermobalance - mass spectrometer system. In the case of biomass materials, however, the mass spectrometric signals proved to contain higher experimental errors than the DTG curves hence they were not used for reaction kinetic evaluations.

\subsection{Pretreatment of the biomass samples}

As it has been mentioned already, equations (2) - (4) proved to be applicable only if the amount of impurities is reduced by a dilute acid or a hot-water washing procedure. ${ }^{6}$ The following procedures were applied: 
i) Acid washing at room temperature by $0.1 \mathrm{~mol} / \mathrm{HCl}$ as proposed by DeGroot and Shafizadeh ${ }^{10}:$ a $1 \mathrm{~g}$ sample was placed in $20 \mathrm{ml}$ of $0.1 \mathrm{~mol} / \mathrm{l} \mathrm{HCl}$ and stirred for $4 \mathrm{~h}$ at room temperature. The suspension was filtered and washed with distilled water until neutrality.

ii) The same procedure with $1 \mathrm{~mol} / \mathrm{l}$ acetic acid instead of $\mathrm{HCl}$.

iii) A similar washing by pure, double distilled, $80^{\circ} \mathrm{C}$ water for two hours. (In this case $120 \mathrm{ml}$ water was used for $1 \mathrm{~g}$ sample.)

\subsection{Materials and heating programs}

The samples were arranged into three groups according to their DTG curves. The heating program, $T(t)$, applied in the TG experiments is described in parentheses.

Group I: Samples where the DTG curve is dominated by a single cellulose peak:

a) Pure, highly crystallized Avicel PH105 cellulose. $\left[T(t): 2,5,10,20\right.$ and $80^{\circ} \mathrm{C} / \mathrm{min}$; and $10^{\circ} \mathrm{C} / \mathrm{min}$ following an isotherm of 60 minutes at $\left.260^{\circ} \mathrm{C}\right]$

b) Whatman filter paper \#1 and \#42. $\left(10^{\circ} \mathrm{C} / \mathrm{min}\right)$

c) Sugar cane bagasse samples subjected to 1 hour hydrolysis by dilute acid $\left(5 \mathrm{mM} / 1 \mathrm{H}_{2} \mathrm{SO}_{4}\right)$ at $150^{\circ} \mathrm{C}$ and $175^{\circ} \mathrm{C}$, respectively. $\left(10^{\circ} \mathrm{C} / \mathrm{min}\right)$

d) Sugar cane bagasse and sweet gum samples subjected to 2-minute hydrolysis by pure water at $230^{\circ} \mathrm{C}$. $\left(10^{\circ} \mathrm{C} / \mathrm{min}\right)$

\section{Group II: Cellulose samples containing small amounts of hemicellulose}

a) Technical cellulose samples prepared from an energy cane and wheat straw, respectively, by the ASAM pulping process. ${ }^{11}\left(10^{\circ} \mathrm{C} / \mathrm{min}\right.$. These samples were due to the courtesy of the Federal Research Centre for Forestry and Forest Products, Hamburg.)

b) Sugar cane bagasse after consuming the majority of its hemicellulose content by a preheating of 2 hours at $260^{\circ} \mathrm{C} .\left(10^{\circ} \mathrm{C} / \mathrm{min}\right)$

Group III: Whole biomass samples after reducing their mineral matter content by dilute acid or hot water washing, respectively

a) Sugar cane bagasse samples. (10 and $\left.20^{\circ} \mathrm{C} / \mathrm{min}\right)$

b) Corn stalk samples. $\left(2,5,10^{\circ} \mathrm{C} / \mathrm{min}\right)$ 
c) Energy cane samples. $\left(20^{\circ} \mathrm{C} / \mathrm{min}\right)$

d) IEA-NIST standard bagasse and wheat straw samples. (5 and $\left.20^{\circ} \mathrm{C} / \mathrm{min}\right)$

\section{RESULTS AND DISCUSSION}

\subsection{Kinetic evaluation}

Figure 1 illustrates the least squares kinetic evaluation of a whole biomass sample at a heating rate of $20^{\circ} \mathrm{C} / \mathrm{min}$. The first order reaction kinetics, used for the description of the partial processes, is only a formal approximation of the thermal decomposition of the lignin and hemicellulose components. (The curve belonging to the lignin looks like a flat, slightly curved base line in Figure 1.) The highest partial peak belongs to the cellulose and will be discussed later. More details on the evaluation can be found in our previous work. ${ }^{5,6}$

The results of the evaluation of the series of experiments listed in section 2.3 are summarized in Table 1 which contains the means and standard deviations belonging to the activation energy $(E)$ and the $\operatorname{logarithm}$ of the preexponential factor $(\log A)$ of the cellulose decomposition.

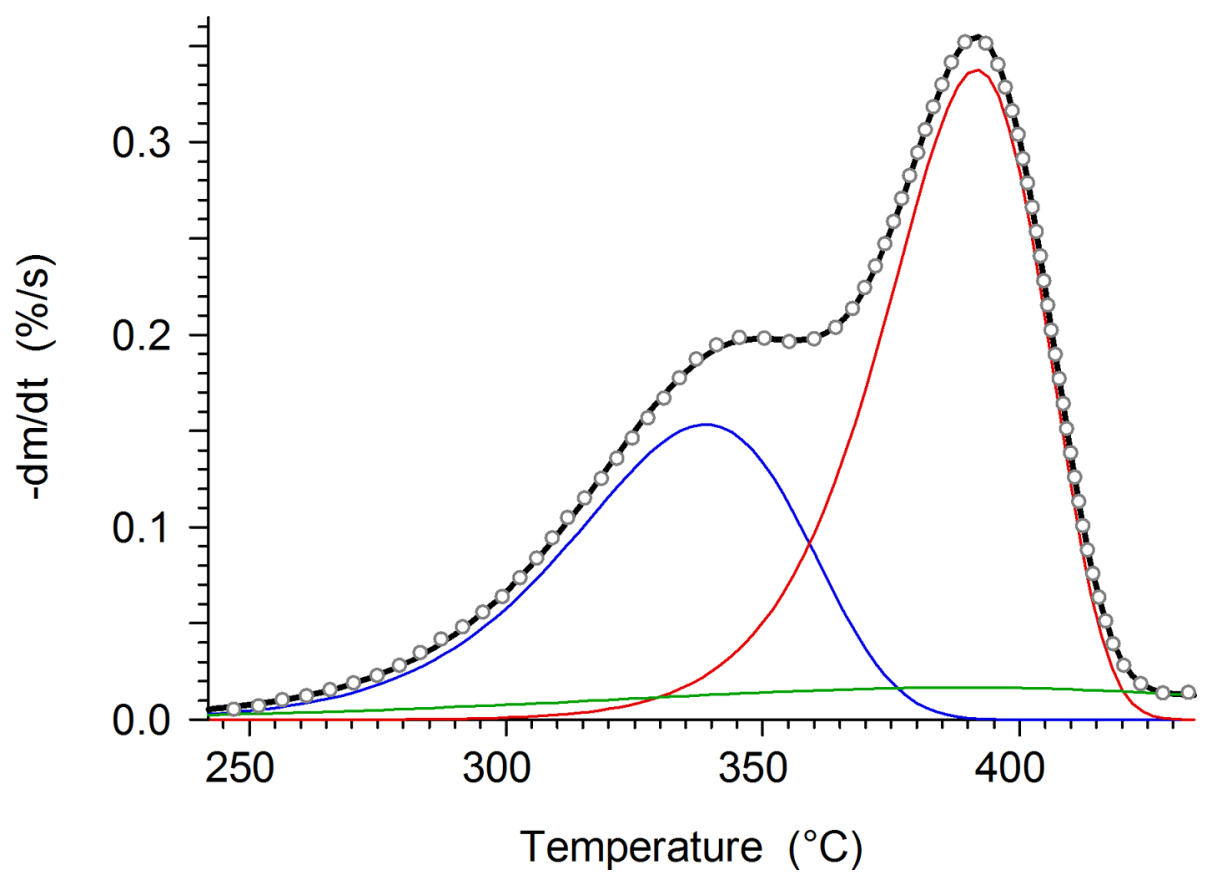

Figure 1: Evaluation of the DTG curve of a hot-water washed bagasse sample. Heating rate: $20^{\circ} \mathrm{C} / \mathrm{min}$. Sample mass: $2 \mathrm{mg}$. Gray circles: observed curve. Black bold line: calculated $-\mathrm{d} m / \mathrm{d} t$. Thin colored lines: $-\mathrm{d} m / \mathrm{d} t$ curves calculated for the decomposition of the components. (See the text.) 
Table 1. Averages and standard deviations of the results of the kinetic evaluations ${ }^{\mathbf{a}}$

\begin{tabular}{|c|c|c|c|c|}
\hline Samples & $\begin{array}{c}\text { Number of } \\
\text { experiments }\end{array}$ & $\begin{array}{l}\text { fitb } \\
\left(\frac{\circ}{0}\right)\end{array}$ & $\begin{array}{c}\mathrm{E} \\
\mathrm{kJ} / \mathrm{mol}\end{array}$ & $\begin{array}{l}\log A \\
\log \mathrm{S}^{-1}\end{array}$ \\
\hline Group I & 19 & $2.1 \pm 0.7$ & $228 \pm 14$ & $16.8 \pm 1.3$ \\
\hline Group II & 4 & $1.5 \pm 0.3$ & $218 \pm 16$ & $15.6 \pm 1.3$ \\
\hline--------- & ------------ & ------- & -------- & --------- \\
\hline roup III & 28 & $0.8 \pm 0.4$ & $217 \pm 16$ & $15.7 \pm 1.4$ \\
\hline 11 & 51 & $1.3 \pm 0.8$ & $221 \pm 16$ & $16.1 \pm 1.4$ \\
\hline
\end{tabular}

a See the Experimental Section for the description of the samples and experimental conditions.

${ }^{\mathbf{b}}$ Deviation between the calculated and the observed - $\mathrm{dm} / \mathrm{dt}$ data expressed in percent of the highest $-\mathrm{dm} / \mathrm{dt}$ value of each experiment.

\subsection{Interpretation}

Keeping in mind the great variety of the samples studied and the well known sensitivity of the cellulose decomposition to impurities, the ca. 8\% scattering of $E$ and $\log A(221 \pm 16$ and $16.1 \pm 1.4$, respectively) is interesting and suggests that these values may have a physical meaning. The most plausible explanation is to assume that the "depolymerization" reaction of the Broido-Shafizadeh model [the lower branch of reaction scheme (1)] dominates the thermal decomposition under the applied experimental conditions. The monomer and oligomer type products (the so called "sirup" fraction) decomposes further in secondary reactions providing the great variety of products reported in the literature of cellulose decomposition. The amount of sirup fraction escaping from the hot reaction zone without cracking into smaller species depend on the type, morphology and size of the given sample and, obviously, on the heating rate, too. In case of $2-3 \mathrm{mg}$ pure cellulose at heating rates $5-80^{\circ} \mathrm{C} / \mathrm{min}$, this amount is about $70 \%$ of the original sample mass. ${ }^{9}$ The following arguments support the existence of a single, rate determining reaction step:

i) Pure cellulose samples exhibit simple, regular DTG peaks with shape, width and peak maxima resembling to those of true, theoretical first order reactions;

ii) The DTG peaks shift with increasing heating rate values and respond to a 1 -hour $260^{\circ} \mathrm{C}$ isothermal section in the same way as the theoretical $-\mathrm{d} m / \mathrm{d} t$ curves of the true first order reactions do;

iii) The DTG curves are similar to the simultaneously measured MS intensity curves in TG-MS experiments $;^{9}$ 
iv) The well known strong dependence of the amount of tar-fraction on the thickness of the cellulose samples;

v) The similarity of the DTG peaks of pure cellulose samples to the partial $-\mathrm{d} m / \mathrm{d} t$ peaks calculated from the DTG curves of cellulose containing biomass samples by a kinetic evaluation based on equations (2) (4).

Nevertheless, we would like to emphasize that not all of the biomass samples we studied could be described by equations (2) - (4). Two different sunflower stems, a hardwood and a pine sample resulted in $\log A$ and $E$ significantly different from the values listed in Table 1, hence these samples were excluded from the calculation of the means and standard deviations in Table 1. Probably the simple washing procedures outlined in the Experimental Section failed to remove sufficient quantites of the inorganics in those cases.

\subsection{About the so called "Kinetic Compensation Effect"}

It is well known in the literature of thermal analysis that the scattering of $E$ is more or less correlated with the scattering of $\log A$. The phenomenon is called the "kinetic compensation effect" and was discussed for cellulose data by Agrawal. ${ }^{4}$ We also observed this correlation though in a much smaller range (see Figure 2). In our opinion, the correlation shown in Figure 2 can be due to commonplace mathematical relations. Briefly, we can say that a $(E, \log A)$ parameter pair obtained by the least squares evaluation of an experimental curve defines a theoretical curve with peak position close to the experimental peak position. Let us characterize the peak position by the temperature where $60 \%$ of the original cellulose is converted. This value, denoted by $T_{0.6}$, is close to the peak temperature, $T_{\text {peak. }}{ }^{12}$ Substituting $T_{0.6}$ into any of the well-known linear approximations of the kinetic equation of the nonisothermal first order reactions ${ }^{13}$ we obtain

$\ln A-E / \mathrm{R} T_{0.6} \cong \mathrm{const}+\ln \beta$

where $\beta$ is the constant heating rate. Our experiments indicate that the relative precision of $1 / \mathrm{R} T_{0.6}$ is much better than that of $E$ or $\ln A$, hence equation (6) is approximately a linear constraint for the scattering of $E$ or $\ln A$. Strictly speaking, there are separate equations of type (6) at each heating rate $\beta$, but these equations are close to each other. The solid lines in Figure 2 show, from top to bottom, equation (6) at $\beta=5,10$ and $20^{\circ} \mathrm{C} / \mathrm{min}$. The slope of the equations were determined by the average of the observed $T_{0.6}$ values, $624.0,637.6$, and $656.8 \mathrm{~K}$, respectively. 


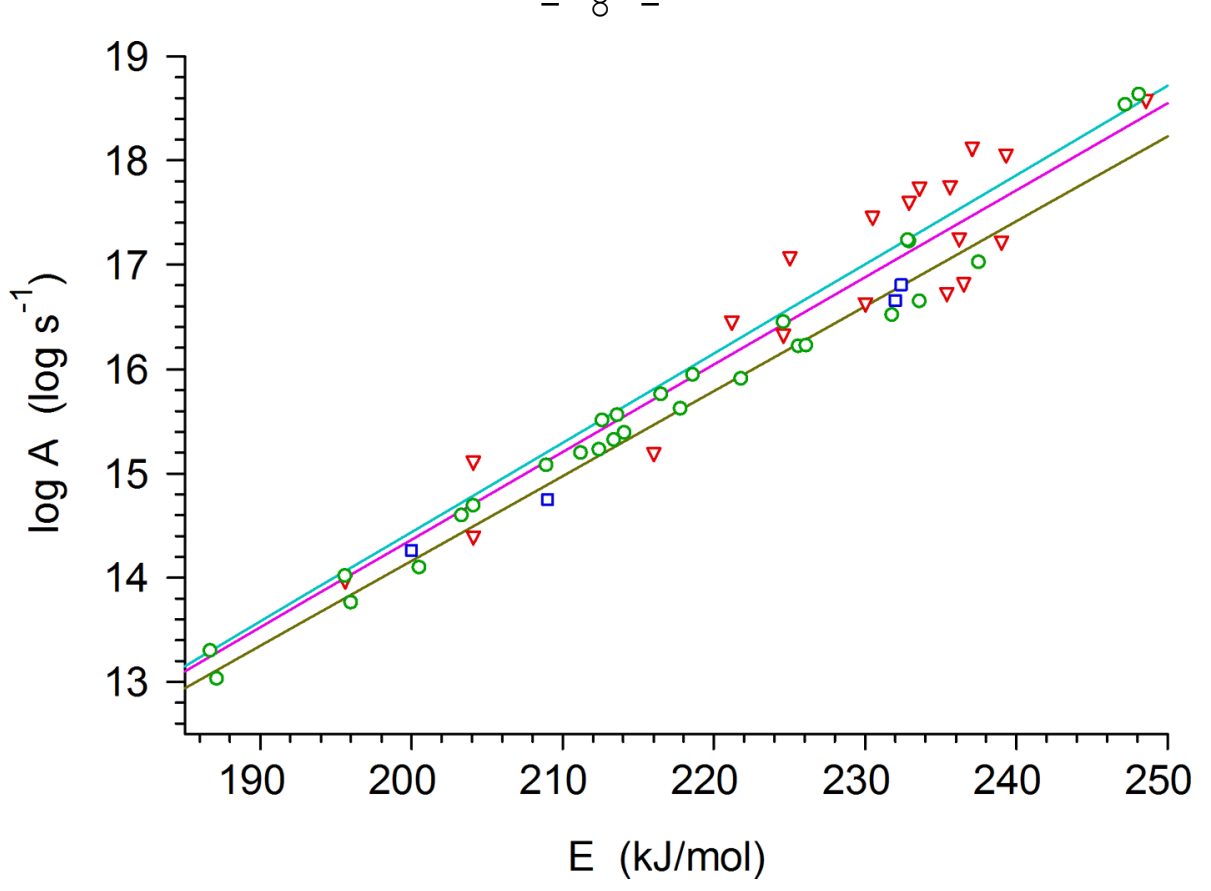

Figure 2: Correlation between the scattering of the $E$ and $\log A$ values. Solid lines from top to bottom: equation (6) at heating rates of 5,10 , and $20^{\circ} \mathrm{C} / \mathrm{min}$, respectively. Points: $(E, \log A)$ data pairs calculated from the experiments of Group I ( $\nabla)$, Group II $(\square)$, and Group III ( $\bigcirc)$, respectively.

\subsection{Extrapolations to higher heating rates}

The position and the width of a given $-\mathrm{d} m / \mathrm{d} t$ curve will be characterized by $T_{0.6}$ and $\left(T_{0.6}-T_{0.3}\right)$, respectively. We look for the means and standard deviations of these values at high heating rates. The most straightforward approach has been chosen: the extrapolation was carried out separately for each experiment. Hence $T_{0.6}$ and $\left(T_{0.6}-T_{0.3}\right)$ values were calculated by solving differential equation (3) at each of the obtained $(E, \log A)$ parameter pairs. Heating rates $1,10,100$ and $1000^{\circ} \mathrm{C} / \mathrm{s}$ were used. The advantage of this approach is that the standard deviation of $T_{0.6}$ and $\left(T_{0.6}-T_{0.3}\right)$ can be directly calculated in this way. The results are shown in Table 2. The data indicate that, for example, a cellulose sample hardly can be heated above $527 \pm 23{ }^{\circ} \mathrm{C}$ without a $60 \%$ decomposition if the real heating rate in the sample is not exceeding the magnitude of $1000^{\circ} \mathrm{C} / \mathrm{s}$. The $-\mathrm{d} m / \mathrm{d} T=-\beta^{-1} \mathrm{~d} m / \mathrm{d} t$ curves belonging to the data of Table 2 are shown in Figure 3. The kinetic parameters of these curves were chosen so that the $T_{0.6}$ and $\left(T_{0.6}-T_{0.3}\right)$ values in Figure 3 are exactly equal to the means listed in Table 2. The display of $-\mathrm{d} m / \mathrm{d} T$ instead of $-\mathrm{d} m / \mathrm{d} t$ serves to scale the curves to approximately equal height. 
Table 2. Extrapolated peak position $\left(T_{0.6}\right)$ and peak width $\left(T_{0.6}-T_{0.3}\right)$ values ${ }^{\text {a }}$

\begin{tabular}{|c|c|c|c|}
\hline $\begin{array}{l}\text { Heating } \\
\text { rate }\end{array}$ & $T_{0.6}$ & $T_{0.6}-T_{0.3}$ & $\begin{array}{l}\text { Symbol in } \\
\text { Figure } 3\end{array}$ \\
\hline${ }^{\circ} \mathrm{C} / \mathrm{s}$ & ${ }^{\circ} \mathrm{C}$ & ${ }^{\circ} \mathrm{C}$ & \\
\hline------- & ------- & --------- & --- \\
\hline 1 & $394 \pm 12$ & $14.8 \pm 1.3$ & $\rightarrow-$ \\
\hline 10 & $433 \pm 15$ & $16.6 \pm 1.6$ & $\boldsymbol{\Lambda}$ \\
\hline 100 & $477 \pm 18$ & $18.6 \pm 1.9$ & $\bullet-$ \\
\hline-------- & ------ & --------- & \\
\hline 1000 & $527 \pm 23$ & $21.1 \pm 2.4$ & 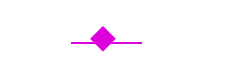 \\
\hline
\end{tabular}

a The extrapolation is based on all of the experiments listed in section 2.3. The values following the \pm sign are standard deviations.

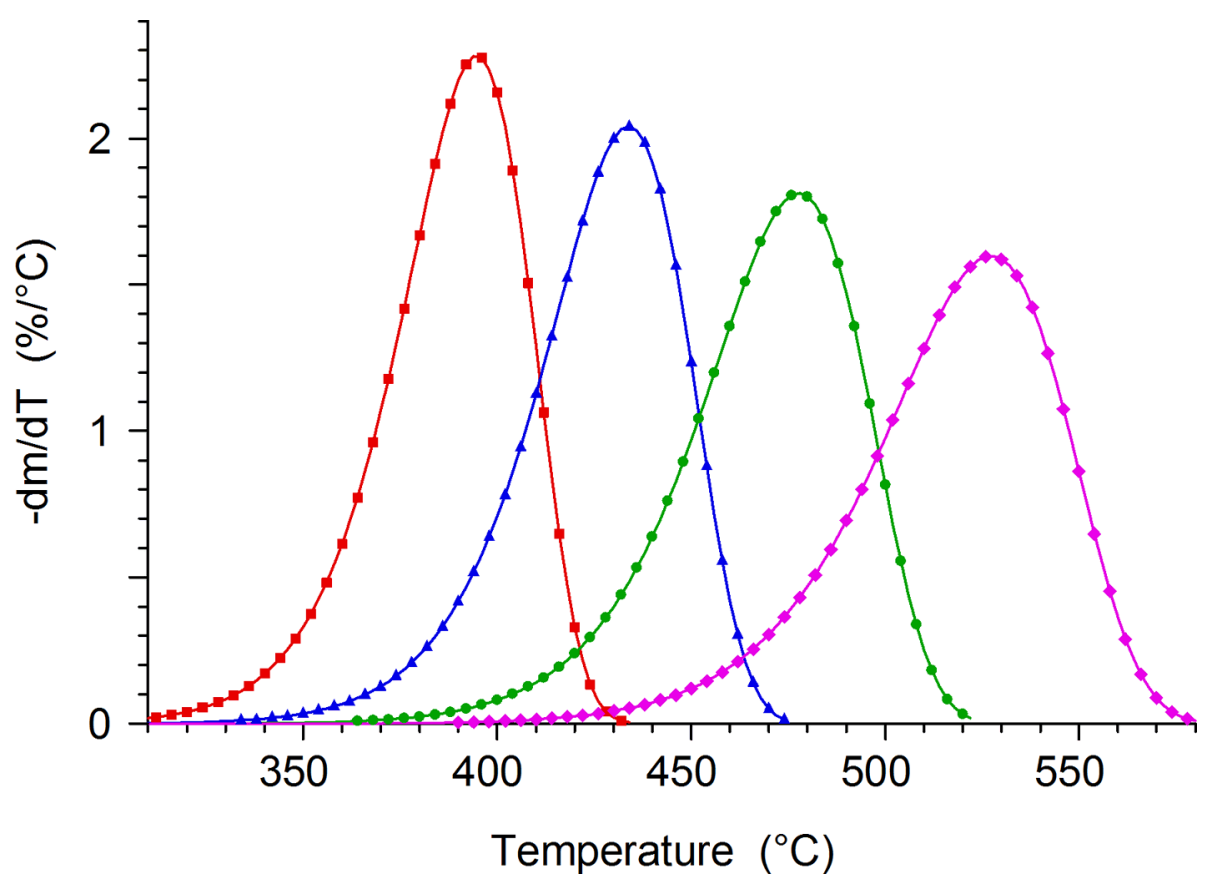

Figure 3: $-\mathrm{d} m / \mathrm{d} T$ curves belonging to the mean $T_{0.6}$ and $\left(T_{0.6}-T_{0.3}\right)$ values listed in Table 2 . From left to right: $1^{\circ} \mathrm{C} / \mathrm{s}(-), 10^{\circ} \mathrm{C} / \mathrm{s}(-), 100^{\circ} \mathrm{C} / \mathrm{s}(\multimap)$ and $1000^{\circ} \mathrm{C} / \mathrm{s}(-)$.

\subsection{Limiting factors}

It is well known that the maximum reaction rate of the reactions controlled by or consisting of a single rate controlling step is approximately proportional to the heating rate at linear $T(t)$ programs. (See e.g. Figure 3, where curves $-\mathrm{d} m / \mathrm{d} T=-\beta^{-1} \mathrm{~d} m / \mathrm{d} t$ from $\beta=1$ to $\beta=1000{ }^{\circ} \mathrm{C} / \mathrm{s}$ have roughly the same 
magnitude.) Hence one can accept, as a rough approximation, that the sample thickness should be inversely proportional to the heating rate in order to avoid heat and mass transfer problems. In our experiments the thickness of the sample layer was in the order of $100 \mu \mathrm{m}$. Hence extrapolations to a hundred times higher heating rate, for example, apply only to the pyrolysis of a few distinct grains of diameters in the order of $1 \mu \mathrm{m}$.

We should like to emphasize that the prediction of the effects of the heat and mass transfer problems is not trivial. Generally, mass transfer limits are expected to slow down a decomposition process. In the case of cellulose, however, the presence of the reaction products during the decomposition can start autocatalytic reactions and can turn the process exothermic. ${ }^{7,8}$ Consequently, we cannot predict how the transport problems of the high heating rate pyrolysis effect the decomposition temperature. The present paper deals only with reactions under chemical kinetic control.

Finally, we should like to repeat here that our work is based on a reaction mechanism observed in the temperature range $250-400^{\circ} \mathrm{C}$. It is possible that other chemical reactions may enter into the competition at higher temperatures and consume the cellulose below the temperatures listed in Table 2 . In this way the extrapolations of the present work may represent upper limits for the cellulose decomposition temperatures at high heating rates and negligible heat and mass transfer effects.

\section{ACKNOWLEDGMENT}

This research program was funded by the National Science Foundation (grant INT 8914934), the US Hungarian Science and Technology Joint Fund (grant 22/90), the Hungarian National Research Fund (OTKA, grant 3077/91) and the Coral Industries Endowment.

\section{REFERENCES}

1. A.Broido and M.Weinstein, Low temperature isothermal pyrolysis of cellulose. In Proc. Third Internat. Conf. Thermal Analysis, vol 3, H.G.Wiedemann (Editor), Birkhäuser Verlag, Basel, 1972, pp 285-296.

2. A.Broido and M.A.Nelson, Char yield on pyrolysis of cellulose. Combust. Flame., 24, 263-268 (1975).

3. A.G.W.Bradbury, Y.Sakai and F.Shafizadeh, A kinetic model for the pyrolysis of cellulose. J. Appl. Polym. Sci., 23 (1979) 3271-3280.

4. R.K.Agrawal, Compensation effect in the pyrolysis of cellulosic materials. Thermochim. Acta, 90, 347-351 (1985)

5. G.Várhegyi, M.J.Antal,Jr, T.Székely and P.Szabó, Kinetics of the thermal decomposition of cellulose, hemicellulose and sugar cane bagasse. Energ. Fuel., 3, 329-335, (1989)

6. G.Várhegyi, P.Szabó, M.J.Antal, Jr.: Reaction kinetics of the thermal decomposition of cellulose and hemicellulose in biomass materials. In Advances in Thermochemical Biomass Conversion (Ed. by T. Bridgwater), Volume 2, Elsevier, in press.

7. W.S.L.Mok, M.J.Antal, Jr., P.Szabó, G.Várhegyi and B.Zelei, Formation of charcoal from biomass in a sealed reactor. Ind. Eng. Chem. Res., 31, 1162-1166, (1992). 
8. G.Várhegyi, P.Szabó, W.S.L.Mok, M.J.Antal, Jr., Kinetics of the thermal decomposition of cellulose in sealed vessels at elevated pressures. Effects of the presence of water on the reaction mechanism. J. Anal. Appl. Pyrol., 26, 159-174, (1993).

9. G.Várhegyi, M.J.Antal, Jr., T.Székely, F.Till and E.Jakab, Simultaneous thermogravimetric - mass spectrometric studies on the thermal decomposition of biopolymers. Part 1: Avicel cellulose in the presence and absence of catalysts. Energy Fuels, 2, 267-272, (1988).

10. W.F.DeGroot and F.Shafizadeh, The influence of exchangeable cations on the carbonization of biomass. $J$. Anal. Appl. Pyrol., 6, 217-232 (1984).

11. R.Patt and O.Kordaschia, Herstellung von Zellstoffen unter Verwendung von alkalischen Sulfitlösungen mit Zusatz von Anthrachinon und Methanol. Das Papier, 40(10A) V1-V8 (1986)

12. G.Várhegyi and T.Székely, Reaction kinetics in thermal analysis: The sensitivity of kinetic equations to experimental errors. A mathematical analysis. Thermochim. Acta, 57, 13-28, (1982).

13. J.Sesták, On the applicability of the $p(x)$ function to the determination of reaction kinetics under nonisothermal conditions. Thermochim. Acta, 3, 150-154, (1971). 